\title{
Effects of Health Promotion Behavior on Exercise Addiction and Leisure Satisfaction among Chinese Male Bodybuilding Participants
}

\author{
Wenjing Chen ${ }^{1}$, Yansen $\mathrm{Li}^{2}$, Hyun-chul Cho ${ }^{3}$, Hyun-ryun $\mathrm{Kim}^{4}$ \\ ${ }^{1}$ Student, Department of Physical Education, Woosuk University, Korea, \\ bunnybae911@gmail.com \\ ${ }^{2}$ Student, Department of Physical Education, Woosuk University, Korea, \\ yansenli@qq.com \\ ${ }^{3}$ Professor, Department of Physical Education, Woosuk University, Korea, \\ chojudo@hanmail.net \\ ${ }^{4}$ Researcher, Sports Welfare Convergence Research Institute, Woosuk University, Korea, \\ khr0615@naver.com \\ Corresponding author: Hyun-ryun Kim
}

\begin{abstract}
In this study, male bodybuilding participants in Harbin, China in 2020 were selected as the subjects. The cluster sampling method was used, and a total of 200 samples were collected. To confirm the relationship between exercise addiction and leisure satisfaction between male bodybuilding participants' health promotion behavior, questionnaires were designed according to the selfadministration law. A total of 185 questionnaires were used for the final analysis, excluding 15 copies of data judged to be insincere from the recovered questionnaires. In order to meet the purpose of this study, data judged to contain insincere negative answers or unreliable responses among the collected questionnaires are deleted from the analysis, and the questionnaires judged to be reliable are coded, and analyzed using the statistical program SPSS Windows 26.0. The version was entered and analyzed as follows. Frequency analysis was performed to derive general characteristics, and exploratory factor analysis and reliability verification Cronbach's alpha were performed to secure validity and reliability between items. In order to analyze the relationship between exercise addiction and leisure satisfaction in the health promotion behavior of Chinese male bodybuilding participants, correlation analysis and multiple regression analysis were performed to derive the following research results. First, health promotion behaviors (eating habits, exercise, stress management, interpersonal relationships, selfactualization, and health responsibility) were found to have a partial positive (+) effect on exercise addiction. Second, health promotion behaviors (eating habits, exercise, stress management, interpersonal relationships, self-actualization, health responsibility) were found to have a partial positive (+) effect on leisure satisfaction. In addition, the limitations existing in this study and suggestions for follow-up studies are presented as follows. First, since this study selects Chinese men living in northern China as bodybuilding participants, it is difficult to disseminate the results of this study nationwide, and it has limitations in showing only the characteristics and personal opinions of the participants. Second, the subject of this study adopts the principle of random selection in the sample selection process, and uncontrollable factors such as the home economy and growth environment may affect the results.
\end{abstract}

Keywords: Health Promotion, Exercise Addiction, Leisure Satisfaction, Bodybuilding, Participants

Received: May 13, 2021; $1^{\text {st }}$ Review Result: June 29, 2021; $2^{\text {nd }}$ Review Result: August 17, 2021

Accepted: September 30, 2021 


\section{Introduction}

\subsection{The Necessity of the Research}

Benefiting from the sustained development of China's economy and society, people's rich material life has made corresponding changes in their ideology. With the implementation of the Outline of the National Fitness Program and the Sports Law of the People's Republic of China, people's lifestyles and attitudes have gradually changed. For example, more and more people are constantly increasing their demand for sports. Accordingly, people pay more attention to the idea of keeping fit. In this context, fitness has evolved into one of the lifestyles that young people are keen on at present. At the same time, the importance of fitness has aroused widespread concern in academic circles. To put it concretely, the sociology and pedagogy gradually take fitness as the research category of the discipline. With the development of national sports and the increase of people's health awareness, more and more people are willingly devoting themselves to various sports. Some people are extremely uncomfortable if they do not go to the gym for a day and even start to feel mentally guilty. Others can not sleep if they do not complete their exercise ration that day. There is no doubt that exercise is good for the body and mind, but it is important to note that too much exercise may not only cause physical damage, but may also lead to exercise addiction, which is harmful to the body and mind. Many studies have shown that the causal mechanisms of exercise addiction are complex and related to psychology and physiology. So, it is necessary to explore the causes of exercise addiction, and health enhancing behaviors that including self-actualization, exercise, interpersonal relationships, health responsibilities, and stress management as some of the factors that influence exercise addiction. In addition, health behaviors as well as healthy lifestyles make people's leisure life extremely satisfying. Many studies have shown that human health behaviors are closely related to leisure satisfaction, and there are fewer analyses for the population of fitness participants. Based on this, the purpose of this research is to explore the influence of health promotion behavior on exercise addiction and leisure satisfaction of male bodybuilding participants in their 20s in China.

With the increase of leisure time in modern society, the number of people enjoying life sports is increasing rapidly. Influenced by the rapidly changing modern society, the gradually diversified people undoubtedly need professional and systematic leisure services, expecting to improve their quality of life by participating in various leisure activities. In particular, various factors related to health have been considered as the basic factors to improve the quality of life, and the increasing participation in sports activities also reflects its increasingly significant importance[1].

The vast majority of bodybuilding participants. usually concentrate on sports with the same idea. They breathe in the same space and enjoy sports. For this reason, they can establish information and interpersonal relationships with each other. From the perspective of sociology, it is helpful for Bodybuilding Participants to form a positive attitude towards life[2].

In theory, the bodybuilding refers to the "sports activities carried out to keep healthy, muscular and balanced strength[3]. Bodybuilding, as a kind of scientific sport, is beneficial to eliminate nervous emotions, aiming to promote healthy, vigorous and balanced physical development. Promoting the healthy lifestyle is defined as a kind of multi-dimensional model of self-oriented activities and concepts, which can ensure and help to improve self-realization and personal achievement as well as happiness[4].

The exercise addiction can be described in various technical terms, including forced exercise and exercise dependence. In general, the exercise addiction is defined as the dependence on regular exercise, which is characterized by withdrawal symptoms, including physiological and psychological factors, within 24 to 36 hours after the exercise stops[5].

Considering the difficulties faced by researchers in concept or measurement methods, the 
phenomenon of the exercise addiction has not been actively discussed. Therefore, it is difficult to know whether the exercise addiction is an actual disease. Nevertheless, compared with shopping addiction, gambling, alcoholism, and internet addiction, the population suffering from the exercise addiction is relatively large. The population of the exercise addiction often span all ages. From the perspective of sociology, sports always belong to the encouraged behavior. Therefore, it can be seen that the higher the degree of specialization of a certain sport, the more people will be immersed in it[6].

Leisure satisfaction reflects the pleasure and satisfaction of individuals participating in leisure activities, which is an important factor that determines the choice and participation and re-participation as well as stop of leisure activities[7]. Continuous participation in leisure sports will have positive effects on one's body and mood. This view has been effectively proved in a large number of previous researches[8][9].

Therefore, the purpose of this study is to provide important data related to the health-promoting behavior of Chinese male bodybuilding participants, to identify factors affecting the health-promoting behavior of the participants, and to provide basic data for understanding exercise addiction and leisure satisfaction.

\subsection{Research Models and Assumptions}

The research model related to the influence of health-promoting behavior of Chinese male Bodybuilding Participants on exercise addiction and leisure satisfaction is shown in [Fig. 1].

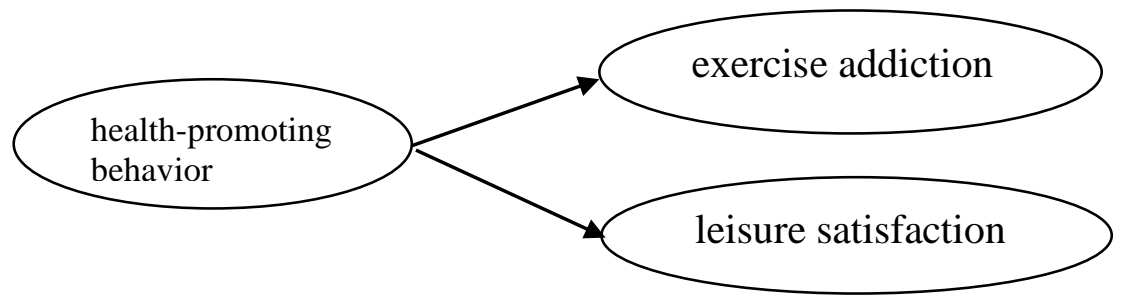

[Fig. 1] Research Model

First, the health-promoting behavior among Chinese male bodybuilding participants will have an impact on their exercise addiction..

Secondly, the health-promoting behavior among Chinese male bodybuilding participants will have an impact on their leisure satisfaction.

\section{Research Methodology}

\subsection{Research Sujects}

Initially, a total of 200 Chinese male bodybuilding praticipants in Harbin, China were collected by cluster sampling method. In the interest of confirming the relationship between health-promoting behaviors and exercise addiction as well as leisure satisfaction among male fitness participants, this research designed the corresponding questionnaire based on self-evaluation method. After removing 15 data judged as dishonest from the collected questionnaires, a total of 185 questionnaires were used for final analysis. The general characteristics of the participants in this research are detailed in [Table $1]$. 
[Table 1] The General Characteristics of the Participants ( $\mathrm{N}=185)$

\begin{tabular}{|c|c|c|c|}
\hline Characteristic & Division & Personnel (N) & Frequency $(\%)$ \\
\hline \multirow{4}{*}{ Education } & High school graduation & 12 & 6.5 \\
\hline & Attending university & 116 & 62.7 \\
\hline & University Graduation & 34 & 18.4 \\
\hline & Graduate school & 23 & 12.4 \\
\hline \multirow{5}{*}{ Athletic career } & Less than 6 months & 62 & 33.5 \\
\hline & 6 months to 1 year & 27 & 14.6 \\
\hline & 1 to 2 years & 44 & 23.8 \\
\hline & 2 to 3 years & 15 & 8.1 \\
\hline & More than 3 years & 37 & 20 \\
\hline \multirow{5}{*}{$\begin{array}{l}\text { Participation } \\
\text { frequency }\end{array}$} & 1 day a week & 34 & 38.9 \\
\hline & 2 day a week & 29 & 14.1 \\
\hline & 3 day a week & 24 & 13 \\
\hline & 4 day a week & 26 & 15.7 \\
\hline & 5 or more days a week & 72 & 18.4 \\
\hline \multirow{5}{*}{ Time } & About 30 minutes & 38 & 20.5 \\
\hline & 1-2 hours & 121 & 65.4 \\
\hline & 2-2 hours 30 minutes & 20 & 10.8 \\
\hline & 2-3 hours & 2 & 1.1 \\
\hline & More than 3 hours & 4 & 2.2 \\
\hline
\end{tabular}

\subsection{Research Tool}

Aquestionnaire was used as a measuring tool in this research to measure the relationship between the established variables. Moreover, all the questions in the questionnaire are based on previous research and related theories. On the premise of ensuring reliability and validity, all the questions have been revised and supplemented according to the purpose of this research. The contents of the questionnaire are shown in [Table 2], with the detailed description as follows.

[Table 2] Questionnaire Contents ( $\mathrm{N}=185)$

\begin{tabular}{ccc}
\hline Composition indicator & Contents & Number of models \\
\hline \hline $\begin{array}{c}\text { The general characteristics } \\
\text { of the participants }\end{array}$ & Education(1), Athletic career(1), Participation frequency(1), Time(1) & 4 \\
\hline Health-promoting behavior & $\begin{array}{c}\text { Eating habits(5), exercise (5), stress management(5), interpersonal } \\
\text { relationship (4), self-realization(4), health responsibility(4) }\end{array}$ & 27 \\
\hline Exercise addiction & Withdrawal symptoms(10), sports desire(7), emotional attachment(6) & 23 \\
\hline Leisure satisfaction & $\begin{array}{c}\text { Social satisfaction(6), emotional satisfaction(5), physical } \\
\text { satisfaction(5), environmental satisfaction(4), educational } \\
\text { satisfaction(4) }\end{array}$ & 24 \\
\hline
\end{tabular}




\subsubsection{Health-promoting Behaviors}

The questionnaire related to the health-promoting behaviors is mainly composed of 48 questions in HPLP(Health Promoting Lifestyle Profile), a health-promoting lifestyle measurement tool developed by Walker et al(1987)[4]. This research supplemented the tools used by [10-12] and [13][14]. Finally, the questionnaire consists of 27 questions involving 6 sub-factors, among which 5 questions are related to exercise, 5on eating habits, 4on self-realization, 5on stress management, 4on interpersonal relationship. as well as 4on health responsibility. In addition, the questions in the questionnaire are designed and composed in accordance with Likert's five-point scale (from "strongly disagree" (onepoint) to "strongly agree" (five-points).

\subsubsection{Exercise Addiction}

In terms of analyzing and studying the questionnaire of exercise addiction, this research uses the EAQ(Exercise Addiction Questionnaire) created by [15]. The questionnaire consists of 23 questions involving 3 sub-factors, among which 10 questions are related to withdrawal symptoms, 7 on sports desire, and 6 on emotional attachment. In addition, all the questions in the questionnaire are designed and composed in accordance with Likert's five-point scale.

\subsubsection{Leisure Satisfaction}

After [16] revised the questionnaire of Korean leisure satisfaction scale development and feasibility verification, the questionnaire was put into use. The questionnaire consists of 24questions involving 5 sub-factors, including 5items related to physical satisfaction, 5on emotional satisfaction, 4 on educational satisfaction, 4on environmental satisfaction, and 6on social satisfaction. In addition, the questions in the questionnaire are designed and composed in accordance with Likert's five-point scale.

\subsection{Effectiveness and Reliability of the Survey Tools}

In this research, the effectiveness and reliability of the survey tools were verified by the following methods. To be specific, first of all, in the interest of verifying the validity of the questionnaire used in , this research conducted an expert review with three physical education professors as the center, and then verified the validity of the contents of the questionnaire, such as clarity, authenticity and applicability. Furthermore, this research made an exploratory factor analysis of the questionnaire. To ensure the reliability of the same set of variables, the coefficient of Cronbach's $\alpha$ was calculated in this research, with the results shown in the [Table 3], [Table 4] and [Table 5].

\subsubsection{Health-promoting Behaviors}

In this research, exploratory factor analysis and reliability verification were carried out on the health-promoting behaviors questionnaire, and the results are shown in [Table 3]. Among the 27 problems, 7 problems(\#4, \#6, \#7, \#11, \#15, \#16, \#27) with factor load lower than .40 were deleted. The remaining 20 questions can be divided into 6 sub-factors (i.e., exercise, eating habits, stress management, self-realization, interpersonal relationship and health responsibility). The cumulative value of total variance explanation was $62.115 \%$, KMO value was .853 , and significance was .000, which indicates that the effectiveness of the structure is guaranteed. Through analysis, Cronbach' $\alpha$ coefficients of sub-factors extracted in this research were .700 for eating habits, .769 for exercise, .701 for stress management, .706 for interpersonal relationship, .702 for self-realization and .702 for health responsibility, proving the existence of internal consistency. 
[Table 3] Results of Exploratory Factor Analysis and Reliability Analysis of Health Promotion Behavior Scale $(\mathrm{N}=185)$

\begin{tabular}{|c|c|c|c|c|c|c|c|}
\hline Model & Factor1 & Factor2 & Factor3 & Factor4 & Factor5 & Factor6 & Cronbach' $\alpha$ \\
\hline Eating habits1 & .785 & .058 & -.030 & .175 & .112 & .098 & \multirow{4}{*}{.700} \\
\hline Eating habits2 & .781 & .016 & .043 & .068 & .123 & .177 & \\
\hline Eating habits5 & 689 & .172 & .097 & .124 & .192 & -.025 & \\
\hline Eating habits3 & .514 & .214 & .213 & -.080 & -.057 & .018 & \\
\hline Self-realization 22 & .141 & .706 & .173 & .023 & .065 & .032 & \multirow{4}{*}{.702} \\
\hline Self-realization 23 & .072 & .681 & .092 & .235 & .103 & .066 & \\
\hline Self-realization 21 & .170 & .668 & .071 & .038 & .080 & .234 & \\
\hline Self-realization 20 & .061 & .569 & .025 & .381 & .309 & .094 & \\
\hline Exercise10 & .060 & .131 & .842 & .178 & .158 & .075 & \multirow{3}{*}{.769} \\
\hline Exercise9 & .120 & .176 & .818 & .211 & .069 & .040 & \\
\hline Exercise8 & .090 & .057 & .672 & .005 & .173 & .190 & \\
\hline Interpersonal relationship18 & .071 & .079 & .289 & .741 & .153 & .247 & \multirow{3}{*}{.706} \\
\hline Interpersonal relationship19 & .139 & .094 & .036 & .729 & .054 & .185 & \\
\hline Interpersonal relationship17 & .053 & .316 & .146 & .648 & .188 & .037 & \\
\hline Health responsibility 25 & .010 & .092 & .168 & .104 & .757 & -.044 & \multirow{3}{*}{.702} \\
\hline Health responsibility 24 & .163 & .221 & .047 & .175 & .729 & .182 & \\
\hline Health responsibility 26 & .265 & .080 & .215 & .079 & .683 & .204 & \\
\hline Stress management14 & .101 & .167 & .110 & .101 & .208 & .784 & \multirow{3}{*}{.701} \\
\hline Stress management 13 & -.011 & .336 & .233 & .097 & .114 & .725 & \\
\hline Stress management 12 & .174 & -.045 & .029 & .315 & -.032 & .661 & \\
\hline Eigenvalues & 5.784 & 1.682 & 1.428 & 1.295 & 1.172 & 1.062 & \\
\hline Dispersion(\%) & 28.919 & 8.408 & 7.142 & 6.473 & 5.862 & 5.31 & \\
\hline Cumulative(\%) & 28.919 & 37.327 & 44.47 & 50.942 & 56.805 & 62.115 & \\
\hline
\end{tabular}

Kaiser-Meyer-Olkin $=.853$

Bartlett=1754.441 df=190, sig=.000

\subsubsection{Exercise Addiction}

In this research, exploratory factor analysis and reliability verification were carried out on the questionnaire of the exercise addiction, and the results are shown in [Table 4]. Among the 23 problems, 2 items(\#17, \#18) with factor loads lower than .40 were deleted. The remaining 21 questions can be divided into three sub-factors (i.e., withdrawal symptoms, sports desire and emotional attachment). The cumulative value of total variance explanation was $64.885 \%$, KMO was .946, and significance was .000 , which proved the validity of the structure. After reliability analysis of the extracted sub-factors, Cronbach' $\alpha$ coefficient calculated by this research was high, which is .918 for withdrawal symptoms, .908 for exercise desire and .887 for emotional attachment, proving the existence of internal consistency. 
[Table 4] Exploratory Factor Analysis and Reliability Analysis Result of Exercise Addiction Scale (N=185)

\begin{tabular}{|c|c|c|c|c|}
\hline Model & Factor1 & Factor2 & Factor3 & Cronbach' $\alpha$ \\
\hline Withdrawal symptoms3 & .780 & .075 & .256 & \multirow{10}{*}{.918} \\
\hline Withdrawal symptoms2 & .772 & .144 & .250 & \\
\hline Withdrawal symptoms8 & .763 & .301 & .108 & \\
\hline Withdrawal symptoms9 & .735 & .339 & -.090 & \\
\hline Withdrawal symptoms10 & .701 & .352 & -.116 & \\
\hline Withdrawal symptoms1 & .683 & .135 & .352 & \\
\hline Withdrawal symptoms7 & .659 & .144 & .311 & \\
\hline Withdrawal symptoms5 & .656 & .254 & .363 & \\
\hline Withdrawal symptoms 4 & .628 & .179 & .311 & \\
\hline Withdrawal symptoms6 & .572 & .303 & .322 & \\
\hline Exercise desire15 & .269 & .756 & .323 & \multirow{6}{*}{.908} \\
\hline Exercise desire14 & .185 & .737 & .384 & \\
\hline Exercise desire11 & .260 & .725 & .314 & \\
\hline Exercise desire13 & .246 & .696 & .336 & \\
\hline Exercise desire12 & .359 & .682 & .230 & \\
\hline Exercise desire16 & .223 & .660 & .386 & \\
\hline Emotional attachment22 & .271 & .260 & .768 & \multirow{5}{*}{.887} \\
\hline Emotional attachment20 & .198 & .353 & .737 & \\
\hline Emotional attachment19 & .110 & .353 & .723 & \\
\hline Emotional attachment 21 & .256 & .357 & .673 & \\
\hline Emotional attachment23 & .236 & .338 & .663 & \\
\hline Eigenvalues & 10.304 & 2.225 & 1.098 & \\
\hline Dispersion $(\%)$ & 49.065 & 10.593 & 5.228 & \\
\hline Cumulative(\%) & 49.065 & 59.658 & 64.885 & \\
\hline
\end{tabular}

Kaiser-Meyer-Olkin $=.946$

Bartlett $=3983.888 \mathrm{df}=210, \mathrm{sig}=.000$

\subsubsection{Leisure Satisfaction}

In this research, exploratory factor analysis and reliability verification were carried out for the health-promoting behaviors survey tool, and the results are shown in [Table 5]. Among the 24 problems, 5 problems(\#4, \#5, \#6, \#10, \#11) with factor load lower than .40 were deleted. The remaining 19 questions can be divided into five sub-factors (i.e., physical satisfaction, emotional satisfaction, educational satisfaction, environmental satisfaction and social satisfaction). The total variance explanation cumulative value was $72.76 \%$, KMO was .911, and the significance was .000, which indicates that the structural effectiveness is guaranteed. After the reliability analysis of the extracted sub-factors, Cronbach' $\alpha$ coefficient calculated by this research was high, which is .848 for social satisfaction, .805 for emotional satisfaction, .871 for physical satisfaction, .876 for environmental satisfaction and .844 for educational satisfaction, proving the existence of internal consistency. 
[Table 5] Exploratory Factor Analysis and Reliability Analysis Result of Leisure Satisfaction Scale $(\mathrm{N}=185)$

\begin{tabular}{|c|c|c|c|c|c|c|}
\hline Model & Factor1 & Factor2 & Factor3 & Factor4 & Factor5 & Cronbach' $\alpha$ \\
\hline Physical satisfaction 13 & .840 & .227 & .172 & .148 & .116 & \multirow{5}{*}{.871} \\
\hline Physical satisfaction12 & .824 & .212 & .152 & .186 & .153 & \\
\hline Physical satisfaction14 & .679 & .093 & .319 & .151 & .221 & \\
\hline Physical satisfaction 15 & .660 & .212 & .334 & .280 & .130 & \\
\hline Physical satisfaction16 & .472 & .064 & .233 & .377 & .228 & \\
\hline Educational satisfaction24 & .172 & .846 & .169 & .173 & .041 & \multirow{4}{*}{.844} \\
\hline Educational satisfaction 23 & .177 & .845 & .223 & .057 & .131 & \\
\hline Educational satisfaction 22 & .143 & .838 & .288 & .141 & .116 & \\
\hline Educational satisfaction 21 & .193 & .471 & -.004 & .344 & .186 & \\
\hline Environmental satisfaction 18 & .243 & .141 & .837 & .213 & .120 & \multirow{5}{*}{.876} \\
\hline Environmental satisfaction19 & .195 & .307 & .776 & .182 & .107 & \\
\hline Environmental satisfaction 17 & .335 & .186 & .769 & .182 & .073 & \\
\hline Environmental satisfaction 20 & .393 & .341 & .468 & .250 & .185 & \\
\hline Social satisfaction2 & .218 & .167 & .222 & .826 & .145 & \\
\hline Social satisfaction1 & .140 & .166 & .275 & .779 & .111 & \multirow[t]{2}{*}{.848} \\
\hline Social satisfaction 3 & .269 & .156 & .110 & .751 & .210 & \\
\hline Emotional satisfaction8 & .124 & .089 & .120 & .187 & .866 & \multirow{6}{*}{.805} \\
\hline Emotional satisfaction9 & .264 & -.013 & .137 & .152 & .803 & \\
\hline Emotional satisfaction7 & .120 & .336 & .044 & .116 & .728 & \\
\hline Eigenvalues & 8.408 & 1.73 & 1.503 & 1.175 & 1.008 & \\
\hline Dispersion $(\%)$ & 44.252 & 9.107 & 7.912 & 6.186 & 5.303 & \\
\hline Cumulative(\%) & 44.252 & 53.359 & 61.271 & 67.457 & 72.76 & \\
\hline
\end{tabular}

Kaiser-Meyer-Olkin $=.911$

Bartlett=3384.65 df=171, sig=.000

\subsection{Survey Procedure}

First of all, the researchers explained the purpose and significance of the research by communicating with participants from different regions online. Secondly, after obtaining the consent of data collection, the researcher and assistant researcher met the subjects directly at the appointed time and collected the corresponding data. While collecting data, researchers directly explained the research purpose and significance to the subjects. With their consent, the researchers issued the questionnaire to the subjects and asked them to fill it out according to the self administration method. Subsequently, the researchers immediately collected the completed questionnaires on the spot.

\subsection{Data Processing}

In the interest of effectively achieving the purpose of this research, the collected questionnaires which were judged to be dishonest or unreliable were deleted from the analysis. At the same time, the statistical program SPSS Windows 26.0 Version was used to analyze the questionnaires which were judged to be reliable.

Through frequency analysis, this research obtained the general characteristics of the questionnaire. In addition, this research ensures the validity and reliability of the questions through exploratory factor 
analysis and reliability verification for Cronbach's alpha. In order to analyze the relationship between health-promoting behaviors, sports addiction and leisure satisfaction of Chinese male bodybuilding participants, the sudy usesd correlation analysis and multiple regression analysis to acquire the following research results.

\section{Results}

\subsection{Correlation Analysis}

In this research, the matrix correlation analysis method of Pearson was mainly used to calculate the correlation coefficient, so as to confirm the directionality and correlation among the dimensions. The results are shown in [Table 6]. It is found that the relationship among the variables is consistent with the hypothesis, and the correlation coefficient is lower than the multicollinearity standard value of .80 . This indicates that the multicollinearity is reasonable.

The correlation analysis revealed a positive relationship between each subfactor of health enhancing behavior, exercise addiction, and leisure satisfaction.

[Table 6] Correlation Analysis Result ( $\mathrm{N}=185)$

\begin{tabular}{|c|c|c|c|c|c|c|c|c|c|c|c|c|c|c|c|}
\hline & Variable & 1 & 2 & 3 & 4 & 5 & 6 & 7 & 8 & 9 & 10 & 11 & 12 & 13 & 14 \\
\hline \multirow{6}{*}{$\begin{array}{c}\text { Health } \\
- \\
\text { promo } \\
\text { ting } \\
\text { behavi } \\
\text { or }\end{array}$} & Eating habits & 1 & & & & & & & & & & & & & \\
\hline & $\begin{array}{c}\text { Self- } \\
\text { realization }\end{array}$ & $\begin{array}{l}.348 \\
* *\end{array}$ & 1 & & & & & & & & & & & & \\
\hline & Exercise & $\begin{array}{c}.266 \\
* *\end{array}$ & $.363 * *$ & 1 & & & & & & & & & & & \\
\hline & $\begin{array}{l}\text { Interpersonal } \\
\text { relationship }\end{array}$ & $\begin{array}{l}.295 \\
* *\end{array}$ & $.472 * *$ & $.401^{* *}$ & 1 & & & & & & & & & & \\
\hline & $\begin{array}{c}\text { health } \\
\text { Responsibilit } \\
y\end{array}$ & $\begin{array}{c}.361 \\
* *\end{array}$ & $.428 * *$ & $.393^{* *}$ & $.410^{* *}$ & 1 & & & & & & & & & \\
\hline & $\begin{array}{c}\text { stress } \\
\text { management }\end{array}$ & $\begin{array}{l}.284 \\
* *\end{array}$ & $.402 * *$ & $.341^{* * *}$ & $.458^{* *}$ & $.352 * *$ & 1 & & & & & & & & \\
\hline \multirow{3}{*}{$\begin{array}{l}\text { Exerci } \\
\text { se } \\
\text { addicti } \\
\text { on }\end{array}$} & $\begin{array}{l}\text { Withdrawal } \\
\text { symptoms }\end{array}$ & $\begin{array}{c}.305 \\
* *\end{array}$ & $.202 * *$ & $.334 * *$ & $.196 * *$ & $.266^{* *}$ & $.174 * *$ & 1 & & & & & & & \\
\hline & Sports desire & $\begin{array}{l}.190 \\
* *\end{array}$ & $.221 * *$ & $.419 * *$ & $.231 * *$ & $.316^{* * *}$ & 0.069 & $.642 * *$ & 1 & & & & & & \\
\hline & $\begin{array}{l}\text { Emotional } \\
\text { attachment }\end{array}$ & $\begin{array}{l}.283 \\
* *\end{array}$ & $.230 * *$ & $.494 * *$ & $.240 * *$ & $.263^{* * *}$ & $.148^{*}$ & $.582 * *$ & $.745 * *$ & 1 & & & & & \\
\hline \multirow{5}{*}{$\begin{array}{l}\text { Leisur } \\
\text { e } \\
\text { satisfa } \\
\text { ction }\end{array}$} & $\begin{array}{c}\text { physical } \\
\text { satisfaction }\end{array}$ & $\begin{array}{l}.256 \\
* *\end{array}$ & $.456^{* *}$ & $.476^{* * *}$ & $.484 * *$ & $.471^{* *}$ & $.405 * *$ & $.210 * *$ & $.289 * *$ & $.325^{* *}$ & 1 & & & & \\
\hline & $\begin{array}{l}\text { educational } \\
\text { satisfaction }\end{array}$ & $\begin{array}{l}.178 \\
* *\end{array}$ & $.401 * *$ & $.445^{* *}$ & $.408 * *$ & $.467 * *$ & $.370 * *$ & $.268 * *$ & $.314 * *$ & $.357^{* *}$ & $.511 * *$ & 1 & & & \\
\hline & $\begin{array}{c}\text { environment } \\
\text { al } \\
\text { satisfaction }\end{array}$ & $\begin{array}{l}.292 \\
* *\end{array}$ & $.451 * *$ & $.453^{* *}$ & $.388 * *$ & $.481^{* * *}$ & $.476 * *$ & $.277 * *$ & $.273 * *$ & $.321 * *$ & $.679 * *$ & $.566 * *$ & 1 & & \\
\hline & $\begin{array}{c}\text { social } \\
\text { satisfaction }\end{array}$ & $\begin{array}{l}.320 \\
* *\end{array}$ & $.387 * *$ & $.508^{* * *}$ & $.449 * *$ & $.435^{* *}$ & $.396 * *$ & $.304 * *$ & $.357^{* *}$ & $.419^{* *}$ & $.592 * *$ & $.472 * *$ & $\begin{array}{l}.563 \\
* *\end{array}$ & 1 & \\
\hline & $\begin{array}{l}\text { emotional } \\
\text { satisfaction }\end{array}$ & $\begin{array}{l}.167 \\
* * \\
\end{array}$ & $.262 * *$ & $.287^{* * *}$ & $.312^{* *}$ & $.359^{* *}$ & $.261 * *$ & $.178 * *$ & $.295^{* *}$ & $.273^{* *}$ & $.483 * *$ & $.382 * *$ & $\begin{array}{l}.388 \\
* * \\
\end{array}$ & $\begin{array}{l}.438 \\
* *\end{array}$ & 1 \\
\hline
\end{tabular}

\subsection{The Effects of Health-promoting Behaviors on the Exercise Addiction}

As shown in [Table 7], this research determined the causal relationship between Chinese male bodybuilding participants' health-promoting behaviors and sports addiction through multiple regression analysis. 
The effects of sub factors of the health-promoting behaviors on the exercise addiction are as follows. To be specific, the health-promoting behaviors can explain $25.6 \%\left(\mathrm{R}^{2}=.256\right)$ of the variation in sports addiction, showing an excellent model fitting degree $(\mathrm{p}<.01)$. The regression equation demonstrates that the $\mathrm{F}$ value is 16.079. In short, this research proves that the sub-factors of the health-promoting behaviors have a positive influence on exercise $(\beta=.369, \mathrm{p}<.001)$.

[Table 7] Multiple Regression Analysis on the Effects of Health Promotion Behavior on Exercise Addiction $(\mathrm{N}=185)$

\begin{tabular}{|c|c|c|c|c|c|c|}
\hline & & B & Std E & $\beta$ & $\mathrm{t}$ & $\mathrm{p}$ \\
\hline \multirow{7}{*}{$\begin{array}{l}\text { Exercise } \\
\text { addiction }\end{array}$} & ( Constant) & 1.220 & 0.236 & & 5.167 & $0.000 * * *$ \\
\hline & Eating habits & 0.158 & 0.054 & 0.168 & 2.936 & 0.004 \\
\hline & Self-realization & 0.017 & 0.057 & 0.018 & 0.291 & 0.771 \\
\hline & Exercise & 0.325 & 0.052 & 0.369 & 6.195 & $0.000 * * *$ \\
\hline & $\begin{array}{l}\text { Interpersonal } \\
\text { relationship }\end{array}$ & 0.026 & 0.060 & 0.028 & 0.439 & 0.661 \\
\hline & $\begin{array}{c}\text { Health } \\
\text { responsibility }\end{array}$ & 0.107 & 0.055 & 0.122 & 1.958 & 0.051 \\
\hline & Stress management & -0.071 & 0.053 & -0.081 & -1.334 & 0.183 \\
\hline
\end{tabular}

$* * * \mathrm{p}<0.001$

\subsection{The Effects of Health-promoting Behaviors on the Leisure Satisfaction}

[Table 8] shows the causal relationship between health-promoting behaviors and leisure satisfaction of Chinese male bodybuilding participants, which is the result of multiple regression analysis in this research.

[Table 8] Multiple Regression Analysis on the Effects of Health Promotion Behavior on Leisure Satisfaction $(\mathrm{N}=185)$

\begin{tabular}{|c|c|c|c|c|c|c|}
\hline & & B & Std E & $\beta$ & $\mathrm{t}$ & $\mathrm{p}$ \\
\hline \multirow{7}{*}{$\begin{array}{c}\text { Leisure } \\
\text { Satisfaction }\end{array}$} & ( Constant ) & 0.882 & 0.159 & & 5.538 & $0.000 * * *$ \\
\hline & Eating habits & -0.011 & 0.036 & -0.014 & -0.317 & 0.751 \\
\hline & Self-realization & 0.119 & 0.038 & 0.152 & 3.100 & $0.002 * *$ \\
\hline & Exercise & 0.212 & 0.035 & 0.276 & 5.976 & $0.000 * * *$ \\
\hline & $\begin{array}{l}\text { Interpersonal } \\
\text { relationship }\end{array}$ & 0.126 & 0.041 & 0.155 & 3.106 & $0.002 * *$ \\
\hline & $\begin{array}{c}\text { Health } \\
\text { responsibility }\end{array}$ & 0.213 & 0.037 & 0.277 & 5.761 & $0.000 * * *$ \\
\hline & Stress management & 0.131 & 0.036 & 0.172 & 3.637 & $0.000 * * *$ \\
\hline
\end{tabular}

$* * \mathrm{p}<0.01, * * * \mathrm{p}<0.001$

The effect of the sub-factors of the health-promoting behaviors on the leisure satisfaction is as follows. To be specific, the health-promoting behaviors can explain $55.2 \%(\mathrm{R} 2=.552)$ variation in leisure satisfaction, with the $F$ value of $57.684(p<.01)$. In short, sub-factor exercise $(\beta=.276, p<.001)$, health responsibility $(\beta=.277, \mathrm{p}<.001)$ and stress management $(\beta=.172, \mathrm{p}<.001)$ of the health-promoting behaviors have positive effects on leisure satisfaction. 


\section{Discussion Section}

This research systematically analyzed the relationship between health-promoting behaviours of Chinese male fitness participants and exercise addiction and leisure satisfaction. In view of this, this study puts forward two research hypotheses. According to the above analysis results, this research draws the following discussion.

\subsection{The Effects of Health-promoting Behaviors on the Exercise Addiction}

Multiple regression analysis confirmed the influence mechanism of Chinese male bodybuilding participants' health-promoting behaviors on the exercise addiction. The research results can be described as the health-promoting behaviors (i.e., exercise, eating habits, stress management, selfactualization, interpersonal relationship and health responsibility), which has been proved to play a certain role in the formation of sports addiction. To be specific, the sub-factor (exercise) of the healthpromoting behaviors has a significant impact on the exercise addiction. Nonetheless, the sub-factors of the health-promoting behaviors (i.e., eating habits, stress management, self-actualization, interpersonal relationship and health responsibility) have no influence on the exercise addiction.

From the perspective of research results, the research of [17] and [18] support this study. They found that endorphins produced during exercise can bring pleasure and desire. Once the exercise stops, the participant will suffer from irritability due to the decrease of endorphins. In general, the symptoms of sports addiction are caused by low-level endorphins in the brain, which can reduce a series of bad emotions including depression, anxiety, confusion, etc., so that participants can experience excitement and happiness. In other words, repeated endorphin stimulation is beneficial to promote the formation of the exercise addiction.

The previous research results support this research, that is, sports can induce a certain degree of addiction. For this reason, only when one's exercise reaches a certain intensity will the one feels comfortable physically and mentally. When people experience a kind of comfort, they will have the urge to enjoy it again. With the rising sense of accomplishment brought by repeated rewards, the degree of individual sports addiction will deepen accordingly, thus promoting the formation of healthy sports and affecting the exercise addiction.

\subsection{The Effects of Health-promoting Behaviors on the Leisure Satisfaction}

Through multiple regression analysis, this research confirmed the influence of the health-promoting behaviors on the leisure satisfaction of Chinese male bodybuilding participants. According to the research results, it is indicated that the health-promoting behaviors have a certain influence on leisure satisfaction. To put it concretely, the sub-factors (exercise, stress management, self-actualization, interpersonal relationship and health responsibility) of the health-promoting behaviors have a significant impact on leisure satisfaction. However, the sub-factor (eating habits) of the healthpromoting behaviors has no effect on the leisure satisfaction.

The results of [19-21] previous research showed that the health-promoting behaviors of life sports participants have a corresponding impact on leisure satisfaction. In addition, according to the research of [22], it is shown that the higher the participation degree of the health-promoting behaviors of the environmental protection movement participants, the higher their leisure satisfaction. This view is consistent with the results of this research. That is to say, male bodybuilding participants can increase the time to prevent diseases and maintain a healthy life through health-promoting behaviors, and finally improve the quality of life. Consequently, if male fitness participants can prevent diseases and prolong their lives through the health-promoting behaviors, their quality of life will also be improved. 
This means that male bodybuilding participants will have positive effects such as leisure satisfaction and improvement of life quality if they put their mentality aimed at improving health into practice. Through regular exercise to improve physical strength, fitness people's leisure satisfaction has been improved.

Also, a series of factors including stress management, health responsibility, self-realization and interpersonal relationship can bring positive changes to physical, psychological and social problems. In view of the fact that the health-promoting behaviors prevent and reduce the occurrence of adult diseases and improve the quality of leisure life through the hard health management of bodybuilding participants, it is generally believed that various related factors of the health-promoting behaviors will affect leisure satisfaction.

\section{Conclusion and Recommendations}

This research aimed to empirically and reasonably reveal the influence of the health-promoting behaviors on the exercise addiction and leisure satisfaction among Chinese male bodybuilding participants. Based on the aforementioned analysis process, this research drew the following conclusions.

First, partial health-promoting behaviors(exercise) have a positive impact on exercise addiction.

Second, partial health-promoting behaviors(exercise, stress management, self-actualization, interpersonal relationship and health responsibility) have a positive impact on leisure satisfaction.

Third, the subfactors of health-enhancing behavior, exercise addiction, and leisure satisfaction were positively correlated with each other.

In conclusion, the health promotion behavior of Chinese male bodybuilders was found to have an effect on exercise addiction and leisure satisfaction. It provides important data related to the healthpromoting behaviors of Chinese male bodybuilding participants, identifies factors influencing the participants' health-promoting behaviors, and provides basic data for understanding exercise addiction and leisure satisfaction.

On the other hand, the limitations of this research and recommendations for follow-up researches are as follows.

First, given the selection of male bodybuilding participants in their 20s who lived in northern China as the subjects, the results of this research were difficult to be spread across the country. Moreover, there are certain limitations to the characteristics and individual views of the participants.

Second, with regard to the choice of research objects, this research adopted the principle of random selection. Uncontrollable factors, represented by domestic economy and growth environment, are likely to have an impact on the research results.

\section{References}

[1] Jeon Tae-Jun, A Study on Relationships between Self-efficacy and Exercise Addiction in participants of Leisure sports, The Korean Journal of Physical Education, (2005), Vol.44, No.6, pp.267-277.

[2] Kim Geon-Sun, The Effect of Adult Women's Health Club Participation on Health Promotion Behavior and Body Composition, Daegu Catholic University: Physical Education Major Exercise Physiology, Master's Thesis, (2011)

[3] Kim Geum-Ja, Cha Young-Nam, An Effect of Health Promotion Program in Mid-life Women, Journal of Korean Academy of Nursing, (1999), Vol.29, No.3, pp.541-550.

[4] S. N. Walker, K. R. Sechrist, N. J. Pender, The health-promoting lifestyle profile: Development and psychometric characteristics, Nusring Research, (1987), Vol.36, No.2, pp.76-81, https://doi.org/10.1097/00006199-198703000- 
00002

[5] Owen Anderson, Running Science, (First edition), Human Kinetics, (2013)

[6] Kang Shin-Wook, The Actual Condition of Leisure Sports Participants Exercise Addiction and Social-Psychological Characteristics of Exercise Addiction, The Korean Journal of Physical Education, (2013), Vol.52, No.5, pp.121-135, UCI : G704-000541.2013.52.5.028

[7] Y. S. Lim, B. W. Ahn, Development of a measurement tool for leisure satisfaction among Korean adults, Proceeding of the Korean society Leisure, Recreation \& Park seminar, (2011), pp-18-19.

[8] Kang Shin-Wook, The Relationship between Adult Education Program Participation and Leisure Satisfaction, The Korean Journal of Physical Education, (1998), Vol.37, No.4, pp.87-98.

[9] Han Hye-won, The Relation among University Students's Leisure Motivation, Constraints and Life Satisfaction in Leisure Participation, The Korean Journal of Physical Education, (2010), Vol.19, No.3, pp.273-284.

[10] Heo Eun-hee, A study on the relationship between college students' health-promoting behavior and self-efficacy, Graduate School of Social Development, Chung-Ang University, Master's thesis, (1998)

[11] Yeom Sun-kyo, A Study on the Relationship between Cognitive Factors and Behaviors on Health Promotion of Middle-aged Women: Focusing on the Prevention of Osteoporosis, The Journal of Muscle and Joint Health, (2002), Vol.9, No.2, pp.247-256.

[12] Oh Bokja, Predicting Health-Promoting Behaviors in Patients with Stomach Cancer, Journal of Korean Academy of Nursing, (1995), Vol.25, No.4, pp.681-695.

[13] Oh Hyun-ah, (The) Relationships among the Health Promoting Behavior, Pain, Self-esteem, Family Support and Self-efficacy in Patients with Chronic Arthritis, Chungnam National University graduate school, Master's thesis, (2004)

[14] Kang Moon-Jeong, Relationship between Self-Efficacy and Health Promotion Behavior in Elementary School Students, Korea National University of Education Graduate School of Education, Master's Thesis, (2005)

[15] Gyuri Shin, An Exploratory Study for the Development of Leisure Sports Addiction Scale, Graduate School of Ewha Womans University, Master's Thesis, (1999)

[16] Kim Young-jae, The Relationship between Social Background and KoreanVersion of the Leisure Satisfaction Variables amongUniversity Students, Korea Sports Research, (2004), Vol.15, No.2, pp.197-204, UCI : G704001366.2004.15.2.055

[17] Kim Se-hee, Effect of self-set goal approaching on oral health promotion according to caries risk in elementary school children, Chosun University Graduate School of Dentistry, Master's Thesis, (2015)

[18] Lu Hui, Analysis of the Causes and Countermeasures of the "Sport Addiction" Phenomenon of Mass Fitness Crowd, Fight Sports Forum, (2015), Vol.7, No.2, pp.13-15, DOI : 10.13293/j.cnki.tylt.002248

[19] Kim Sik, The relationships between the level of exercise addiction and health promoting lifestyle of bowling participants, Korea Sports University, Master's Thesis, (2015)

[20] Lee Chan-Young, The Effects of Leisure Satisfaction According to the Consumption Propensity of Participants in Living Sports Clubs on Exercise Continuation Intention, Graduate School of Kyunghee University, Master's Thesis, (2016)

[21] Yoon Hyung-ki, Kim Dae-hoon, An analysis of the relation on the health promotion behavior, health status, satisfaction of leisure and quality of life of the senior citizens, The Korean Society of Sports Science, (2011), Vol.20, No.4, pp. 219-230.

[22] Hong Seong-Woo, Health promotion lifestyle, leisure satisfaction and life satisfaction according to LOHAS tendency of eco-friendly sports participants, Kyung Hee University Graduate School of Physical Education, Doctoral dissertation, (2013) 